\title{
Proliferation of Social Computing: Cultural Computing Paradigm
}

\author{
Seemu Sharma \\ Computer Science and \\ Engineering Department \\ Thapar University \\ Patiala, India
}

\author{
Seema Bawa \\ Computer Science and \\ Engineering Department \\ Thapar University \\ Patiala, India
}

\author{
Hitashi Lomash \\ School of Humanities and Social \\ Sciences \\ Thapar University \\ Patiala, India
}

\begin{abstract}
This paper provides a historical perspective of computing technology along with its evolutionary phases. It is a scientific endeavour to understand and further investigate the significant role played by human which leads to the development of innovative technologies. A comprehensive study of invention from personal to cooperative and then to social computing has been done and its impacts have been highlighted. This paper focuses on two aspects explicitly. The first part renders how cultural computing evolved as a technological paradigm. The second part explicates the interaction of culture and technology through dynamics of mind, to define cultural computing.
\end{abstract}

\section{Keywords}

Cultural computing, unconscious mind, culture, dynamics of mind, computing, social computing.

\section{INTRODUCTION}

Cultural Computing is relatively a new field where most of the researchers focus on portraying the impact that computing technology has on the culture. Probably it is the time when cultural computing requires a meticulous understanding as the way it evolved and the underlying interaction of computing and culture. This paper focuses on these two aspects. The first part renders how cultural computing evolved as a technological paradigm from Personal Computing. The second part explicates the interaction of culture and technology, with an attempt to define cultural computing.

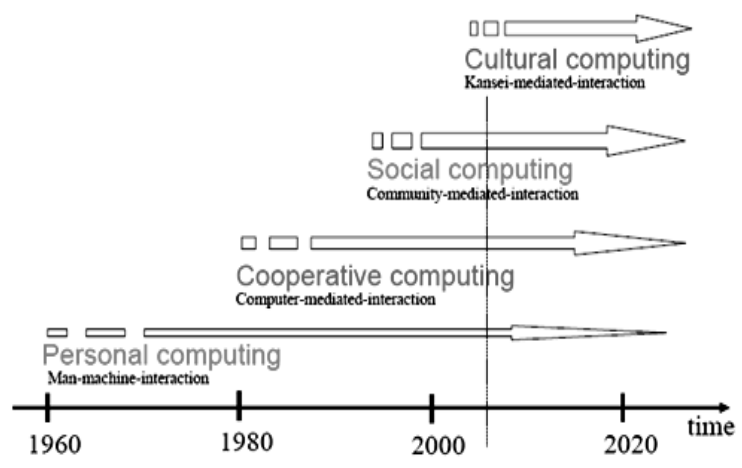

Fig. 1: Growth and Development of Technology in the field of HCI [1]

Considering the importance of computers and technology in $21^{\text {st }}$ century, it would be desirable to undergo current status of computing after its evolutionary phases. From Personal computing to cultural computing, Figure1 would help us have an overview of the growth and development of the technology in the field of Human- Computer Interaction (HCI).

\section{PERSONAL COMPUTING}

The first man- machine interaction took place in 1960s and became the landmark as Personal Computing. Till late 1970s, it was like a dream fir a common man to make use of the personal computer as its use was limited only to information technologists, the hobbyists to learn something new. To become potential computer user, the programming languages, operating systems and hardware helped in computing and heavy calculations keeping its records as data and editing texts, spreadsheets etc. Although the original scholarly abode for HCI was computer science, and its original attention was on personal productivity applications, mainly text editing and spreadsheets, the field had constantly spread and outgrown all boundaries [2]. Beside its limited reach of no collaboration, no sharing and narrow vision, the personal computing extended its domain from desktop to the industries without any timeline.

\subsection{Need for Cooperative Computing}

With expanding horizons, the need to share knowledge between users was realized. Data management became the area of concern. Hence, the need to communicate, share data and to run software remotely arose and led to the birth of the Internet which in the long run created the era for Cooperative Computing.

\subsection{Personal Computing to Cooperative Computing}

Precursor to the Internet, the ARPANET in 1969 became a reality as it helped the researchers at different levels and sites to interact and communicate with each other. The ARPANet was primarily initiated to connect military installations and universities participating in government projects [3].

\section{COOPERATIVE COMPUTING}

The astounding growth of ARPANET in 1980s helped to start the paradigm of Cooperative Computing by evolving the Internet. Interactive multimedia was the main center of attention in this phase. Computer- mediated interaction involved people to produce, share and identify information using networked or non- networked computers that make encoding, transmitting and decoding messages easy to access. Applications such as email, newsgroups, and remote logins etc. evolved a new culture of rapid working and it was attractive to all colleges and universities. As a result, an international nonprofit organization was founded in 1992 named as Internet Society. The Internet Society maintains and enforces standards, ensuring that there is a communication between all the computers on the Internet. It also organizes 
committees that recommend and support new Internet-related technologies and software. It has been found that the Internet doubled in size every 1 or 2 years. Thus, it led to a world that is presently is nowadays known as virtual global village.

\subsection{Need for Social Computing}

With Cooperative Computing, the world became a global village. The interaction between people and organizations became easier and its tremendous want paved the way for the birth of Social Computing. Despite its need and usability, it had concerns regarding safety measures and privacy. The new dimension addressing above issues was referred to as social computing.

\subsection{Cooperative Computing to Social Computing}

Human Computer Interaction (HCI) considers more personalized as well as close communications with constructive experiences while using mobile, portable and ubiquitous technology. While referring to Social Computing, $\mathrm{HCI}$ is about community mediated interaction. The HCI society examined applications such as Computer Supported Cooperative Work (CSCW) and the Internet (e.g. online communities) [1]. Various concepts that have come out in recent years, like ubiquitous, nomadic, mixed-reality computing etc., directs the future of HCI. In general, all these new directions have some common properties: (a) the vanishing computer; (b) the easiness of use and constructive experience and; (c) the community building. Hence, device from where the user is accessing the Internet is not a constraint. Users are mainly interested in benefits, affects and running applications of the computer than the computer itself.

\section{SOCIAL COMPUTING}

Social Computing refers to applications and services that aid combined action and social interaction on the Internet such as blogs, wikis, social networks and discussion forums etc. Social Computing is a new and rising computing paradigm that involves a multi- disciplinary path to evaluate and frame social behaviors on various media and platforms to construct intelligent and interactive applications and results [4]. Social computing is also defined as, "Computational facilitation of social studies and human social dynamics as well as the design and use of information and communication technologies that consider social context [5]". There is a high degree of community formation in social computing, high content creation specifically at user level and range of other characteristics [6]. The success of social computing systems depends on the readiness of the members to contribute and share [7]. Rather than the old and static content on the web sites, social computing technologies are driving up marketing areas for two-way communication, rather than just informing users about the product for promotion. By enabling services such as commenting and discussion on our blog, one is putting effort to promote Social Computing.

\subsection{Social Computing at Glance}

Technology and social factors converge to create social computing [8]. Cheap hardware and software, exponential growth of processing power and storage capacity has made computing power accessible to the masses. Majority of population is striking into technology's power to change social ways of life. Social changes are enhancing the movement of Social Computing. People who are socially motivated are keener to use and adapt this technology. Particularly for today's youth, it has become a part of life. It has been found that twelve to seventeen year old youths in the
US spend $17 \%$ more time online than adults for personal reasons and $155 \%$ more time instant messaging. And each year technology penetrates younger age groups.

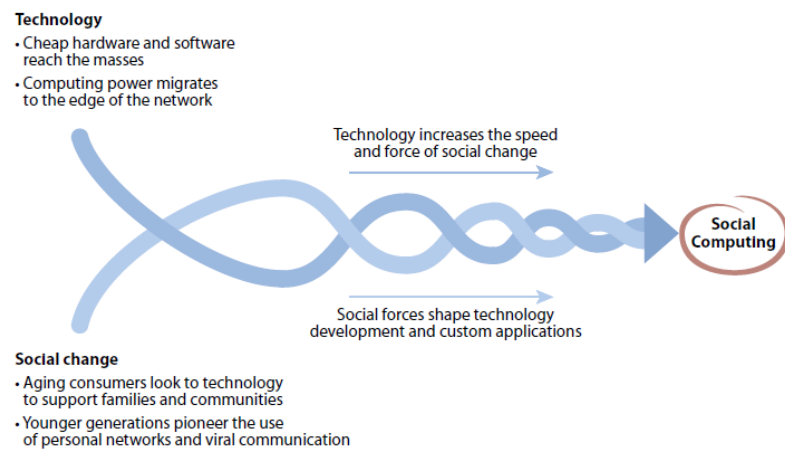

Fig. 2 Technology and Social Factors Converge to Social Computing [8]

The increase in social computing may be due to the increase in usage of the Internet. It is because Internet is readily available through connection on various portable devices like mobile phones, Ipads, laptops, tablets etc. In the 90's, wikis, blogs and many social networking sites like Friendster, MySpace etc were created which revolutionized the computing era. [9] explains how the first commercial text message was sent in December 1992. According to Bordwell [10], the number of text messages sent and received every day, exceeds the total population of the planet. If traditional mass media is looked upon, radio took thirty eight years to reach a market audience of 50 million. Television took thirteen years. And the Internet took only four years to reach the same number of audience. Furthermore, IPod took three years and Facebook, a very popular social networking website took got popularity in just two years. This fast spreading trend has affected the pace of growth.

\section{NEED FOR CULTURAL COMPUTING}

Rauterberg [1] introduced cultural computing as a new paradigm in the field of human computer interaction (HCI) through Kansei mediation. The fundamental concept for this is to provide user with an experience which is equal to Satori [11]. The underlying concept of this is allowing the layers between conscious and unconscious to merge together. This leads to communication of unconscious mind with the conscious mind and vice- versa without any filter. However, he also pointed out the adverse side Satori that a person needs to cross evil border to attain true Satori [11].

Rauterberg claims that Kansei mediation will not have negative side of the Satori as the communication is the active immerse with awareness of consciousness. He mentions that achieving this level of communication is a big challenge. $\mathrm{He}$ used augmented reality (AR) to give user experiences in his research work. As cultural computing addresses underlying and almost unconscious cultural determinants, Rauterberg declares that concepts and projects of cultural computing (like ZENetic Computer [12], Alice in Wonderland [13] etc.) cannot fit to all cultures [13]. So, different cultures worldwide need to have different approaches to address their particular cultural determinants.

In reality, the virtual world of Internet does not have any kind of constraint of these determinants and crosses all the boundaries by connecting all cultures. So, there is a need to understand cultural computing in different perspectives. 
Hence, the idea of dynamics of mind is proposed to understand the concept of cultural computing in the virtual world.

\section{DYNAMICS OF MIND AND CULTURAL COMPUTING}

The concept of cultural computing is inherently interdisciplinary. Having a complimentary aspect, the effect of prevailing technologies on human mind and behaviour is becoming an area of study that needs reflection. It involves culture which can be stated as the entire way of life of the people, including their technology and cultural artifact or everything one would need to become functional member of the society [14] but not a product or a behaviour. Culture is seen as a structure of social control, where people outline their principles, values and behaviour based on the interaction with the environment [15]. Hence, people shape different communities. The rise of the Internet usage has developed a strong potential in forming communities and each community shapes a unique culture [16]. This can be easily seen in social computing scenario also. The users of social networking websites like Facebook, Twitter, LinkedIn etc. form different communities and groups for sharing their ideas, views and data etc. Despite of benefits of social computing, other effects of its usage are coming into being like over usage, effect on mental health, need for affiliation, Internet addiction, cyber crimes etc.

Considering the impact of social computing on human beings, in general, and civilization as a whole, there is a need to direct and understand the interrelationship between society and technology [17].

Computing technology and culture both are the reflections of the mind; computing technology being tangible and culture intangible. According to Freud [18], there are three levels of consciousness: conscious, preconscious and unconscious. Jung [19] further divided the unconscious mind into collective unconscious and personal unconscious.

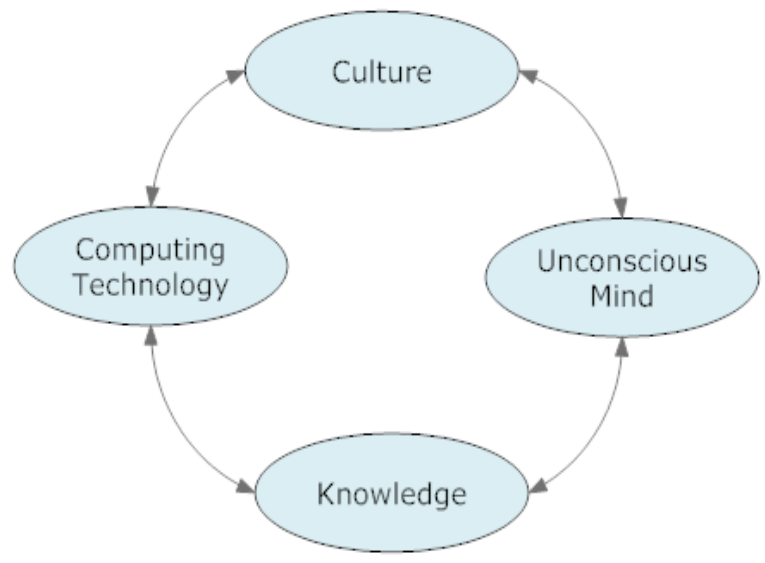

Fig. 3 Relationship between Culture and Computing Technology

The collective unconscious is a part of the psyche which can be differentiated from a personal unconscious by the fact that it does not totally depend on personal experience and therefore is not a personal acquisition but a primitive and archaic experience stored in the unconscious.

It is not wrong to say that the use of the Internet and hence social computing in our lives has pushed into a new virtual culture where behavior of the user and the virtual world, both being intangible, are existent and are affecting each other unnoticed. The Internet makes one feel that he or she is connected to the world. It is indicative of longing of human being for a deeper connection with others and the need for a transcended being. But Internet fakes both of these needs. Internet is interesting because it offers so much freedom that one can easily find his/ her ideal self but it's not same as the social self. The difference is due to the user talking to a computer screen and the user talking to a real person.

This virtual culture of Internet cannot surmount the human's innate culture because the source of knowledge in computing is human mind itself. This knowledge has certainly increased within generations from the unconscious mind and has added to computing and other technologies alongside. Thus, the relationship between unconscious mind and computing technology has been established via knowledge. Our knowledge has become incredibly vast with computing technologies. This is the reason that our unconscious has also reached at a broader level which over a period of time is affecting culture. There is actually a co- evolution of technology and humans and hence culture. So, computing affects a person's culture and vice versa. Hence, it can be said that culture and computing are interrelated (Figure 3). There is a need for the promotion of culture in Cultural Computing due to its vast and diversified nature.

The usage of Internet has become part of our lives. The repetition of the experience of its usage in due course, sets in the conscious and unconscious mind of the user leaving an impression. Today, the Internet and social networking sites' users form a different community. Besides traditional cultural communities, these days, there are communities based on the Internet usage e.g. Facebookers. The point of discussion is the repeated interaction and creating an indeterminate and uncontrolled, unregulated content for the conscious/unconscious mind of the Internet users.

Therefore, based on understanding of dynamics of mind, the definition of cultural computing in the virtual world is proposed as

"The study that understands the phenomenon of interaction of mind (conscious and unconscious) with the virtual world which is unregulated and indeterminate content and the role of computing technology in contriving the culture is called cultural computing",

In this definition, different dimensions of Cultural Computing have been synthesized to give an overview of the field which is vast and engrossing. It covers in itself various other important fields like anthropology, psychology, information and communication technology (ICT) and philosophy. In the interaction using IT tool, one should be able to express the culture [22]. Similarly, the impact of technology on culture has been considered as an inevitable part of historic research [23]. Hence, there is a dire need to use computing to promote cultures in the world so that most of the people would share and disseminate the cultural information using this technology.

\section{CONCLUSION AND FUTURE SCOPE}

To conclude, this paper apprehends the product of virtual experience of computing technology at conscious level getting into our unconscious mind which reflects back in our conscious mind. The role of this paper is to bring to knowledge the importance and need to study cultural computing by which human culture is being altered by the use of computing and technologies in the longer run. Idea of 
dynamics of mind helps to define cultural computing in a constructive way. A detailed review of other aspects and works happened in the field of cultural computing need to be studied in future. There is a need to create cultural archives that needs to be disseminated effectively in the virtual world. Further, study of effects of social computing should be carried out to use cultural computing in an effective manner.

\section{REFERENCES}

[1] Rauterberg, M., "Usability in the Future- explicit and implicit effects in cultural computing," Mensch and Computer, pp. 29- 36, 2006.

[2] Carroll, J. M. 2010. Encyclopedia entry on Human Computer Interaction (HCI) (2009). [Online]. Available: http://www.interaction-

design.org/encyclopedia/human_computer_interaction_h ci.html

[3] Reed, D. 2008. A Balanced Introduction to Computer Science, USA: Pearson Press, ( ISBN- 13: 978-0-13601722-6, ISBN-10: 0-13-601722-3).

[4] King, I., Li, J. and Chan, K. T. 2009. A Brief Survey of Computational Approaches in Social Computing. International Joint Conference on IEEE, pp. 1625- 1632.

[5] Wang F. Y., Carley, K. M., Zeng, D. and Mao, W. "Social computing: From Social informatics to social intelligenc," IEEE Intelligent systems, vol. 22, no. 2, pp. 79-83, 2007.

[6] Parameswaran, M. and Whitson, A. B. "Social Computing: An Overview" Communications of the Association for Information Systems, vol. 19, no. 37, pp. 762-780, 2007.

[7] Motahari, S., Manikopoulos, C., Hiltz, R. and Jones, Q. 2007. Seven Privacy Worries in Ubiquitous Social Computing. In Proceedings of the $3^{\text {rd }}$ Symposium on Usable Privacy and Security ACM, pp. 171- 172

[8] Charron, C., Favier, J. and Li, C. "Social Computing" Forrester Research, 2006.

[9] Urmann D. 2010. How Text Messaging Started. [Online]. Available: http://ezinearticles.com/?HowText-Messaging-Started\&id=1882851.

[10] Bordwell, M. 2013. Copy of Mass Media as Curriculum and Media Literacy. [Online]. Available: https://prezi.com/n5ifo3p9k4sq/copy-of-mass-media-ascurriculum-and-media-literacy/

[11] Nakatsu, R., Rauterberg, M. and Salem, B. "Forms and Theories of Communication: From Multimedia to Kansei Mediation," Multimedia Systems, vol. 11, no. 3, pp. 304312, 2006.

[12] Tosa, N., Matsuoka, S., Ellis, B., Ueda, H. and Nakatsu, R. 2005. Cultural computing with context- aware application: ZENetic computer. In Entertainment Computing- ICEC, Spring Berlin Heidelberg, pp. 13- 23

[13] Rauterberg, M. "From Personal to Cultural Computing: how to assess a cultural experience," uDayIVInformation nutzbar machen, pp. 13-21, 2006.

[14] Inglis, F. 1973. C. Greetz: Culture custom and ethics, Wiley Press.

[15] Hu, J. and Bartneck, C. "Culture Matters- a study on presence in an interactive movie," CyberPsychology and Behavior, vol. 11, no. 5, pp. 529- 535, 2008.

[16] Hongladarom, S. "Global Culture, Local Cultures, and the Internet," AI and Society, vol. 13, no. 4, pp. 389401, 1999.

[17] Sharma, S., Lomash, H. and Bawa, S., "Who Regulates Ethics in Virtual World?," Science and Engineering Ethics, vol. 21, no. 1, pp. 19-28, 2015.

[18] Stoodley, B. H. 1956. The concept of Sigmund Freud, Free Press.

[19] Papadoupoulos, R. K.. 2006. Jungian Psychology: Theory, Practice and Applications, Routledge Press.

[20] 2013 Concept of Archetypes at Carl Jung. [Online]. Availability: http://www.carl-jung.net/archetypes.html. Accessed 29 September 2013.

[21] Hall, C. S. and Lindzey, G. 1957. Theories of Personality. New York: John Willey and Sons.

[22] KyoDaiOcw. 2010. Informatics Symposium Joint Talk "Cultural Computing" Naoko Tosa. [Online]. Available: http://www.youtube.com/watch?v=c3vHcqxONDg.

[23] Sharma, S., Bawa, S. and Lomash, H. "Web presence of Indian Digital Culture," Preservation, Digital Technology and Culture, vol. 44, no. 2, pp. 62-68, 2015. 